\title{
CRESCIMENTO DO MILHO EM FUNÇÃO DA SATURAÇÃO POR BASES E DA ADUBAÇÃO POTÁSSICA ${ }^{1}$
}

\author{
Marcelo Andreotti²*; João Domingos Rodrigues ${ }^{3}$; Carlos Alexandre Costa Cruscioli,7; Euclides \\ Caxambu Alexandrino de Souza ${ }^{5}$; Leonardo Theodoro Büll ${ }^{6}$ \\ ${ }^{2}$ Depto. de Produção Vegetal, Seção Agricultura e Melhoramento Vegetal - FCA/UNESP, Fazenda Experimental \\ Lageado s/n, C.P. 237 - CEP: 18603-970 - Botucatu, SP. \\ ${ }^{3}$ Depto. de Botânica - IB/UNESP, Distrito de Rubião Junior s/n, C.P. 510 - CEP: 18618-000 - Botucatu, SP. \\ ${ }^{4}$ Depto. de Produção Vegetal, Seção Agricultura e Melhoramento Vegetal - FCA/UNESP. \\ ${ }^{5}$ Depto. de Solos e Adubos - FCAV/UNESP, Rodovia Carlos Tonnani, km 5, s/n - CEP: 14870-000 - Jaboticabal, SP. \\ ${ }^{6}$ Depto. de Recursos Naturais, Seção de Ciência do Solo - FCA/UNESP. \\ ${ }^{7}$ Bolsista CNPq. \\ *Autor correspondente <barnaott@bol.com.br>
}

RESUMO: Os teores de $\mathrm{Ca}, \mathrm{Mg}$ e $\mathrm{K}$ no solo interferem no crescimento e na produção das culturas. No entanto, a relação entre esses nutrientes que proporciona o desenvolvimento adequado das plantas varia entre as espécies vegetais. O presente teve por objetivo estudar o desenvolvimento do milho em função da saturação do solo por bases e adubação potássica. O delineamento experimental foi inteiramente casualizado, com quatro repetições, em esquema fatorial 3x2x4, constituindo-se de três solos (Neossolo Quartzarênico, Latossolo Vermelho e Latossolo Bruno), dois valores de saturação por bases (40 e $70 \%$ ) e quatro doses de potássio no solo $\left(0,60,120\right.$ e $\left.240 \mathrm{mg} \mathrm{kg}^{-1}\right)$. O experimento foi conduzido em casa-de-vegetação, utilizando-se 0 milho cv. Zêneca 8392 com uma planta por vaso de 30 L. Aos 29, 57 e 127 dias após a emergência das plântulas, efetuaram-se medidas do número de folhas por planta, altura média das plantas, diâmetro basal do colmo e comprimento médio de entrenós. Após a colheita final determinou-se a produção de grãos por planta. $O$ desenvolvimento e a produção de grãos do milho aumentou até a adição de $60 \mathrm{mg} \mathrm{kg}^{-1}$ de $\mathrm{K}$ ao solo. $\mathrm{O}$ crescimento do milho foi mais rápido no solo mais arenoso, até o florescimento masculino. Solos com maior capacidade de troca catiônica proporcionaram maior comprimento de entrenós. O comprimento médio de entrenós foi inversamente relacionado ao número médio de entrenós por planta, em função do tipo de solo. Palavras-chave: calagem, comprimento de entrenós, altura, número de folhas

\section{CORN GROWTH IN RELATION TO SOIL BASE SATURATION AND POTASSIUM FERTILIZATION}

\begin{abstract}
Calcium, magnesium and potassium contents of soils influence growth and yield of crops, the relationships among those nutrients that result in the best plant development are, however, plant species dependent. The purpose of the present study was to analyse corn growth as a function of potassium fertilization and of the base saturation of the soil. An experiment was set up under greenhouse conditions with an early single corn hybrid "Zeneca 8392" grown in $30 \mathrm{~L}$ pots, filled with three types of soil (one Quartzpsamment and two alic- Haplorthox), with two levels of base saturation (40 and $70 \%$ ) and four rates of potassium $(0,60,120$ e $240 \mathrm{mg} \mathrm{kg}^{-1}$ ). A 3x2x4 completely randomized design was used, with four replications. Plant growth was analysed 29, 57 and 127 days after seedling emergence measuring internode length, leaf number, plant height and basal stem diameter. Plant development and grain yield increased up to a soil $\mathrm{K}$ application of $60 \mathrm{mg} \mathrm{kg}^{-1}$. Growth was rapid until flowering for the sandy soil. Average internode length increased for soils with the highest CEC. The average internode length was inversely related to internode number per plant, depending on soil texture.

Key words: liming, soil texture, length of internodes, plant height, number of leaves
\end{abstract}

\section{INTRODUÇÃO}

A competição entre, magnésio e potássio ocorre durante o processo de absorção radicular, uma vez que utilizam os mesmos sítios de absorção. Entretanto, o efeito negativo do desbalanço de nutrientes somente é detectado a partir do florescimento da cultura do milho, através da determinação do acúmulo de nutrientes e produção de matéria seca. A correção do problema nesse estádio não surtirá mais efeito na produção de grãos. Portanto, a proporção de $\mathrm{K}$ em relação ao $\mathrm{Ca}$ e $\mathrm{Mg}$ deve ser definida na implantação de cultura.

Mortvedt \& Khasawneh (1986) atribuíram ao balanço de nutrientes no solo a responsabilidade por limitações no crescimento das plantas e não só a produção de grãos de sorgo. O desbalanço da relação $\mathrm{K}:(\mathrm{Ca}+\mathrm{Mg})$ no solo para a produção de matéria seca foi linear; sendo assim, tanto adubação potássica como a calagem interferem muito neste processo. Já, Grant \& Racz (1987) afirmaram que, para a cevada, o 
crescimento e a produção de matéria seca foram afetados pelas altas concentrações de $\mathrm{Ca}$ ou $\mathrm{Mg}$ na solução do solo (acima de $8 \mathrm{mmol} \mathrm{L}^{-1}$ ) e que estas não inibiram a absorção de $\mathrm{K}$ pela planta.

Lierop et al. (1979) relataram que a escolha do calcário foi primordial para evitar problemas de deficiência de $\mathrm{Ca}$ ou $\mathrm{Mg}$, principalmente em solos com baixa capacidade de troca catiônica, pois como o reservatório de íons é baixo, a relação $\mathrm{Ca}: \mathrm{Mg}$ do calcário pode proporcionar desbalanço destes e portanto, competição pelos sítios de absorção da planta.

A competição entre $\mathrm{Ca}, \mathrm{Mg}$ e $\mathrm{K}$ pelo mesmo sítio de troca, no processo de absorção, pode resultar no menor acúmulo de um desses elementos tendo como consequência menor produtividade de grãos decorrente do menor desenvolvimento da planta. Assim, as características, número e comprimento de entrenós (Vasilas et al., 1988; Murtadha et al., 1989), diâmetro basal do colmo (Stromberger et al., 1994), número de folhas (Taiz \& Zeiger, 1991) e altura de plantas (Vasilas et al., 1988; Murtadha et al., 1989; Taiz \& Zeiger, 1991) são reduzidas, principalmente, pela deficiência de $\mathrm{Ca}$ e $\mathrm{K}$.

Para melhor desenvolvimento de raízes e parte aérea das plantas de milho em solos ácidos, recomendase a relação Ca:Mg de 3:1 (Silva, 1980). Entretanto, Oliveira (1993), com base na produção de matéria seca de milho, concluiu não existir uma única relação mais adequada entre $\mathrm{Ca}$ e $\mathrm{Mg}$. Os acréscimos na concentração de Ca ou Mg na matéria seca não afetaram o rendimento final do milho, proporcionando apenas maior ou menor concentração dos nutrientes pela competição na absorção, como o relatado por Wilkinson \& Duncan (1993).
A resposta do milho à adubação potássica varia quanto ao tipo de solo, saturação de Ca e Mg na solução e nível inicial deste no solo (Meurer \& Anghinoni, 1993), ao nível de produtividade esperado (Raij et al., 1996), à faixa de aplicação do adubo (Model \& Anghinoni, 1992) e ao material genético estudado (Furlani et al., 1986).

O presente trabalho teve por objetivo avaliar o efeito de duas saturações por bases e adubação potássica, em três solos, sobre o desenvolvimento de plantas de milho.

\section{MATERIAL E MÉTODOS}

O experimento foi conduzido em casa-devegetação climatizada, localizada no Departamento de Ciência do Solo, da Faculdade de Ciências Agronômicas, Campus de Botucatu, UNESP.

Utilizou-se o milho, cultivar Zêneca 8392, descrito como um híbrido simples e precoce. A semeadura foi realizada em 04/03/1997, deixando-se uma planta/vaso. Os solos utilizados foram classificados, segundo Carvalho et al. (1983), como: NQ= Neossolo Quartzarênico $\left(900 \mathrm{~g} \mathrm{~kg}^{-1}\right.$ de areia, $70 \mathrm{~g} \mathrm{~kg}^{-1}$ de argila e $30 \mathrm{~g} \mathrm{~kg}^{-1}$ de silte), LV = Latossolo Vermelho $\left(650 \mathrm{~g} \mathrm{~kg}^{-1}\right.$ de areia, $300 \mathrm{~g} \mathrm{~kg}^{-1} \mathrm{de}$ argila e $50 \mathrm{~g} \mathrm{~kg}^{-1}$ de silte), LB = Latossolo Bruno (190 g $\mathrm{kg}^{-1}$ de areia, $630 \mathrm{~g} \mathrm{~kg}^{-1}$ de argila e $180 \mathrm{~g} \mathrm{~kg}^{-1}$ de silte), cujas principais características encontram-se na TABELA 1.

Para a elevação da saturação por bases, utilizouse uma mistura de carbonatos, na proporção $\mathrm{Ca}: \mathrm{Mg}$ de $4: 1$, ou seja, $4,76 \mathrm{~kg}$ de $\mathrm{CaCO}_{3}+1 \mathrm{~kg}$ de $\mathrm{MgCO}_{3}$ (PRNT $=103,33 \%$ ). As doses da mistura dos carbonatos foram calculadas para os três tipos de solos utilizados pela equação para $\mathrm{NC}=\left(\left(\mathrm{V}_{2}-\mathrm{V}_{1}\right)^{*} \mathrm{~T}\right) / 100$ (Raij et al., 1996) e corresponderam a 0,32 e $1,14 \mathrm{t} \mathrm{ha}^{-1}$ para o Neossolo

TABELA 1 - Caracterização química dos solos utilizados no experimento antes e após a aplicação dos tratamentos.

\begin{tabular}{|c|c|c|c|c|c|c|c|c|c|c|}
\hline Atributo & $\begin{array}{l}\mathrm{pH}\left(\mathrm{CaCl}_{2}\right) \\
0,01 \mathrm{~mol} \mathrm{~L}^{-1}\end{array}$ & M.O. & $\mathrm{P}$ resina & $\mathrm{K}$ & $\mathrm{Ca}$ & $\mathrm{Mg}$ & $\mathrm{H}+\mathrm{Al}$ & SB & CTC & $\mathrm{V}$ \\
\hline & & $\mathrm{g} \mathrm{kg}^{-1}$ & $\mathrm{mg} \mathrm{dm}^{-3}$ & \multicolumn{6}{|c|}{ - } & $\%$ \\
\hline \multicolumn{11}{|c|}{ Caracterização química inicial } \\
\hline NQ & 4,0 & 12 & 4 & 0,5 & 6,0 & 1,0 & 20 & 8,0 & 28 & 28 \\
\hline LV & 4,1 & 38 & 2 & 0,4 & 1,0 & 1,0 & 60 & 2,0 & 62 & 3 \\
\hline LB & 4,0 & 31 & 5 & 0,6 & 3,0 & 1,0 & 109 & 5,0 & 114 & 4 \\
\hline \multicolumn{11}{|c|}{ Caracterização química 30 dias após a calagem } \\
\hline NQ & 5,02 & 7,7 & 154 & 3,11 & 11,0 & 2,8 & 20,9 & 16,9 & 37,8 & 45 \\
\hline LV & 5,05 & 23,8 & 164 & 3,38 & 25,5 & 6,0 & 49,9 & 34,9 & 84,8 & 41 \\
\hline LB & 5,44 & 30,3 & 162 & 3,55 & 45,5 & 10,9 & 42,1 & 59,9 & 102,1 & 59 \\
\hline $\mathrm{V}_{40}$ & 4,82 & 20,43 & 157 & 3,49 & 21,0 & 5,3 & 45,2 & 29,8 & 75,0 & 40 \\
\hline$V_{70}$ & 5,52 & 20,74 & 162 & 3,20 & 33,7 & 7,8 & 30,1 & 44,7 & 74,8 & 60 \\
\hline $\mathrm{K}_{1}$ & 5,19 & 21,42 & 159 & 1,16 & 28,2 & 6,7 & 37,1 & 36,1 & 73,2 & 49 \\
\hline $\mathrm{K}_{2}$ & 5,15 & 20,20 & 155 & 2,50 & 26,8 & 6,4 & 37,6 & 35,7 & 73,3 & 49 \\
\hline $\mathrm{K}_{3}$ & 5,18 & 20,73 & 168 & 4,06 & 26,9 & 6,4 & 38,5 & 37,4 & 75,9 & 49 \\
\hline $\mathrm{K}_{4}$ & 5,16 & 19,18 & 158 & 5,67 & 27,6 & 6,6 & 37,4 & 39,8 & 77,2 & 52 \\
\hline
\end{tabular}

${ }^{1} \mathrm{NQ}$, LV e LB correspondem aos solos: Neossolo Quartzarênico, Latossolo Vermelho e Latossolo Bruno; $V_{40}$ e $V_{70}$ a saturação por bases de 40 e $70 \%$ e $\mathrm{K}_{1}, \mathrm{~K}_{2}, \mathrm{~K}_{3}$ e $\mathrm{K}_{4}$ aos teores de 0,5; 1,5; 3,0 e 6,0 $\mathrm{mmol}_{\mathrm{c}} \mathrm{dm}^{-3}$ de $\mathrm{K}$ aplicados nos solos, respectivamente. 
Quartzarênico, 2,22 e 4,02 t ha-1 para o Latossolo Vermelho e 3,97 e 7,28 $\mathrm{t}^{-1} \mathrm{a}^{-1}$ para o Latossolo Bruno, para elevar o valor de saturação por bases, respectivamente, para 40 e $70 \%$.

Para adubação nitrogenada e fosfatada, seguiu-se a recomendação de Malavolta (1980), adaptada por Andreotti (1995), com aplicação de $200 \mathrm{mg} \mathrm{kg}^{-1}$ de $\mathrm{N}$ e $200 \mathrm{mg} \mathrm{kg}^{-1}$ de $P$ em vasos de $30 \mathrm{~L}$. Na semeadura, aplicaram-se $22,5 \mathrm{~g}$ de MAP/vaso ( $60 \%$ de $\mathrm{P}_{2} \mathrm{O}_{5}$ e $11 \%$ de $\mathrm{N}$ ), correspondendo a $2,48 \mathrm{~g} \mathrm{~N}\left(82,67 \mathrm{mg} \mathrm{kg}^{-1}\right)$ e $13,50 \mathrm{~g} \mathrm{de}_{2} \mathrm{O}_{5}\left(200 \mathrm{mg} \mathrm{kg}^{-1}\right)$. $O$ restante da dose de nitrogênio, $117,33 \mathrm{mg} \mathrm{kg}^{-1}$, foi aplicada em cobertura, aos 25 e 40 dias após a emergência das plântulas (DAE), na forma de sulfato de amônio ( $20 \% \mathrm{~N}$ ), correspondendo a duas aplicações de $8,80 \mathrm{~g}\left(\mathrm{NH}_{4}\right)_{2} \mathrm{SO}_{4} / \mathrm{vaso}$, num total de $3,52 \mathrm{~g}$ de $\mathrm{N}$.

As doses de $\mathrm{K}$ obedeceram os valores limites das classes de fertilidade contidos em Raij et al. (1996), para a cultura do milho, ou seja, original dos solos $(0,5), 1,5$, 3,0 e $6,0 \mathrm{mmol}_{\mathrm{c}} \mathrm{dm}^{-3}$. Foram aplicados, por vaso de $30 \mathrm{~L}$ : 2,17, 4,34 e 8,68 $\mathrm{g}$ de $\mathrm{K}_{2} \mathrm{O}$, respectivamente, para atingir 60,120 e $240 \mathrm{mg} \mathrm{kg}^{-1}$ de K. A fonte utilizada foi o KCl $(60$ $\% \mathrm{~K}_{2} \mathrm{O}$ ), aplicando-se 3,62, 7,24 e 14,48 g KCl/vaso, 5 dias antes da semeadura.

Utilizou-se 0 delineamento experimental inteiramente casualizado, em esquema fatorial, $3 \times 2 \times 4$, constituindo-se de três solos (NQ, LV e LB), dois valores de $\mathrm{V}(40$ e $70 \%)$ e quatro doses de $\mathrm{K}$ no solo $(0,60,120$ e $240 \mathrm{mg} \mathrm{kg}^{-1}$ ), com quatro repetições.

Foram utilizados vasos com capacidade de $35 \mathrm{~L}$, preenchidos com $30 \mathrm{~L}$ de solo da camada de $0-20 \mathrm{~cm}$ peneirado em malha de $7 \mathrm{~mm}$ e seco ao ar. A calagem foi efetuada 30 dias antes da semeadura misturando-se 0 calcário com toda a terra de cada vaso, para melhor reação dos carbonatos. $A$ adubação $\mathrm{N}$ e $\mathrm{P}$, assim como as doses de $\mathrm{K}$ estudadas, foram aplicadas cinco dias antes da semeadura. No momento da semeadura efetuou-se a análise química do solo, por vaso (TABELA 1), segundo metodologia descrita por Ferreira et al. (1990).

O fornecimento de água foi feito periodicamente, avaliando-se a necessidade através da pesagem de quatro vasos para cada tipo de solo, colocando-se a quantidade suficiente para elevar a $100 \%$ da capacidade de campo (CC), sempre que o nível atingia $80 \%$ da CC.

Efetuaram-se três medidas de comprimento de entrenós, número de folhas, altura da planta e diâmetro basal do colmo no período de 25/03/97 a 29/07/97, que foram tomadas aos $29 \mathrm{DAE}$ (início de desenvolvimento dos órgãos reprodutivos), $57 \mathrm{DAE}$ (florescimento masculino) e aos 127 DAE (maturação fisiológica). Após a colheita das plantas, determinou-se a produção de grãos por planta (determinada através da pesagem dos grãos após retirada da espiga e secagem a $13 \%$ de umidade (base úmida)).

\section{RESULTADOS E DISCUSSÃO}

Aos $29 \mathrm{DAE}$, o milho apresentou maior número de folhas no solo arenoso, possivelmente, devido a maior disponibilidade de nutrientes na solução desse solo, nos períodos iniciais de crescimento, e na saturação por bases pretendida de $70 \%$ (TABELA 2).

TABELA 2 - Número de folhas, diâmetro basal do colmo e altura de plantas de milho em diferentes dias após a emergência (DAE) afetados pela saturação por bases e teores de potássio em diferentes solos.

\begin{tabular}{|c|c|c|c|c|c|c|c|c|c|}
\hline \multirow[b]{2}{*}{ Tratamento $^{1}$} & \multicolumn{3}{|c|}{ Número de folhas } & \multicolumn{3}{|c|}{ Diâmetro basal do colmo } & \multicolumn{3}{|c|}{ Altura de plantas } \\
\hline & $29 \mathrm{DAE}$ & $57 \mathrm{DAE}$ & $127 \mathrm{DAE}$ & $29 \mathrm{DAE}$ & $57 \mathrm{DAE}$ & $127 \mathrm{DAE}$ & $29 \mathrm{DAE}$ & $57 \mathrm{DAE}$ & $127 \mathrm{DAE}$ \\
\hline & & & & -------- & & & $\mathrm{cm}-\cdots$ & ----------- & - \\
\hline$N Q$ & $10,23 \mathrm{a}$ & 13,65 & 11,03 & $1,77 \mathrm{a}$ & $1,83 \mathrm{~b}$ & 1,74 & 58,2 a & 186,2 & 257,2 \\
\hline LV & $9,50 \mathrm{~b}$ & 12,78 & 10,62 & $1,73 a b$ & $1,95 \mathrm{a}$ & 1,84 & $49,6 b$ & 183,5 & 262,3 \\
\hline LB & $9,64 \mathrm{~b}$ & 13,03 & 10,56 & $1,63 \mathrm{~b}$ & $1,89 a b$ & 1,77 & $50,0 \mathrm{~b}$ & 190,3 & 272,8 \\
\hline $\mathrm{V}_{40}$ & $9,66 \mathrm{~b}$ & 13,08 & 10,95 & 1,69 & 1,87 & 1,76 & $51,0 \mathrm{~b}$ & $179,7 \mathrm{~b}$ & 260,0 \\
\hline$V_{70}$ & 9,93 a & 13,23 & 10,52 & 1,73 & 1,91 & 1,81 & 54,2 a & 193,6 a & 268,2 \\
\hline $\mathrm{K}_{1}$ & 9,54 & $12,79 b$ & 10,62 & $1,52 \mathrm{~b}$ & $1,70 \mathrm{~b}$ & $1,61 \mathrm{~b}$ & $49,2 \mathrm{~b}$ & $167,0 \mathrm{~b}$ & $248,3 \mathrm{~b}$ \\
\hline $\mathrm{K}_{2}$ & 9,92 & $13,46 \mathrm{a}$ & 10,79 & $1,77 \mathrm{a}$ & $1,91 \mathrm{a}$ & 1,82 a & 53,9 a & $193,0 \mathrm{a}$ & $267,2 a b$ \\
\hline $\mathrm{K}_{3}$ & 9,81 & $13,21 a b$ & 10,75 & $1,78 \mathrm{a}$ & 1,99 a & $1,88 \mathrm{a}$ & 53,4 a & 194,3 a & $269,3 a b$ \\
\hline $\mathrm{K}_{4}$ & 9,90 & $13,17 \mathrm{ab}$ & 10,79 & $1,77 \mathrm{a}$ & 1,96 a & 1,82 a & $53,8 \mathrm{a}$ & $192,4 \mathrm{a}$ & $271,5 \mathrm{a}$ \\
\hline $\mathrm{CV}(\%)$ & 5,92 & 5,90 & 11,92 & 11,21 & 10,47 & 10,19 & 11,21 & 16,58 & 11,24 \\
\hline$S$ & * & & & * & * & & * & & \\
\hline V\% & * & & & & & & * & * & \\
\hline $\mathrm{K}$ & & * & & * & * & * & * & * & * \\
\hline $\mathrm{S} \times \mathrm{V} \%$ & & * & & & & & & & \\
\hline
\end{tabular}


$O$ efeito da adição de $K$ no solo foi significativo, em relação a testemunha, aos $57 \mathrm{DAE}$, próximo ao período de florescimento masculino (TABELA 2). Portanto, podese inferir que, nessa fase de desenvolvimento, a partir de teores de $\mathrm{K}$ no solo considerados médios por Raij et al. (1996), não houve efeito da aplicação de K sobre o número de folhas do milho.

A interação solo e saturação por bases foi significativa aos 57 DAE (TABELA 3). No solo arenoso (NQ), houve aumento do número de folhas com o aumento da saturação por bases, como resultado da maior quantidade de $\mathrm{Ca}$ e $\mathrm{Mg}$, para o crescimento vegetal. Entretanto, dentro dos valores de saturação, de maneira geral, no solo mais arenoso (NQ), o número de folhas emitidas, foi significativamente maior do que no solos argilosos (LV e LB), possivelmente, pelo maior crescimento inicial como verificado aos 29 DAE.

Embora os tratamentos tenham alterado o número de folhas até o florescimento masculino (TABELA 2), aos $127 \mathrm{DAE}$, ou seja, na última avaliação, a planta não apresentou diferenças entre os tratamentos. Dessa forma, os fatores estudados afetam a velocidade de surgimento das folhas, porém não interferem na quantidade final, assim, essa variável é afetada em maior intensidade por fatores genéticos do que externos.

O diâmetro do colmo (TABELA 2) foi alterado pela adição de $\mathrm{K}$ ao solo, em todos os períodos avaliados. As diferenças, no entanto, ocorreram até o teor médio de $\mathrm{K}$ no solo, segundo classificação de Raij et al. (1996), diferindo apenas da testemunha $(0,5 \mathrm{mmol}$ $\mathrm{dm}^{-3}$ ). Tal resultado, demonstra que a adição de $\mathrm{K}$ resultou em colmos mais grossos, sendo mais resistentes ao acamamento e ao quebramento (Karlen et al., 1987). Isso não ocorre porque o potássio faz parte de algum componente estrutural da planta, mas sim, pela ativação enzimática no processo de transporte de $\mathrm{N}$ e conseqüentemente crescimento e desenvolvimento celular, o que confere aumento de tecidos na planta (Stromberger et al., 1994).

TABELA 3 - Número de folhas por planta de milho aos 57 dias após emergência (DAE) em função da saturação por bases em diferentes solos (Desdobramento das interações significativas da análise de variância).

\begin{tabular}{ccc}
\hline \multirow{2}{*}{ Solo $^{1}$} & \multicolumn{2}{c}{ Saturações por bases $(\%)$} \\
\cline { 2 - 3 } & $\mathrm{V}_{40}$ & $\mathrm{~V}_{70}$ \\
\hline $\mathrm{NQ}$ & $13,31 \mathrm{aB}^{2}$ & $14,00 \mathrm{aA}$ \\
LV & $13,00 \mathrm{aA}$ & $12,56 \mathrm{bA}$ \\
LB & $12,94 \mathrm{aA}$ & $13,12 \mathrm{bA}$ \\
\hline
\end{tabular}

${ }^{1} \mathrm{NQ}$, LV e LB correspondem aos solos: Neossolo Quartzarênico, Latossolo Vermelho e Latossolo Bruno.

${ }^{2}$ Médias seguidas da mesma letra, minúscula na vertical e maiúscula na horizontal, não diferem estatisticamente pelo teste de Tukey a $5 \%$.
Até o florescimento masculino (57 DAE), houve efeito marcante do tipo de solo sobre o diâmetro do colmo (TABELA 2), pois em solos mais argilosos, a CTC é maior e portanto a quantidade de bases trocáveis é maior (TABELA 1). O cálcio tem função estrutural na parede celular, e o $\mathrm{K}$ atua como ativador enzimático. Resultados semelhantes, atribuídos ao $\mathrm{Ca}$, foram relatados por Murtadha et al. (1989) e ao K, por Vasilas et al. (1988).

A altura de plantas de milho (TABELA 2) foi influenciada pela elevação do teor de $\mathrm{K}$ no solo até a adição da dose de $60 \mathrm{mg} \mathrm{kg}^{-1}$, em todas as épocas de amostragem. No início do desenvolvimento das plantas de milho (29 DAE), a altura foi maior no solo arenoso (NQ) e na saturação por bases de $70 \%$, permanecendo esse efeito da $V \%$ até o florescimento masculino (57 DAE). Tanto esta variável, como o diâmetro do colmo e o número de folhas devem ter sido influenciadas pela quantidade de $\mathrm{Ca}$ e $\mathrm{K}$ disponível (TABELA 1). No Neossolo Quartzarênico, o número de entrenós em todas as épocas de avaliação, foi significativamente maior que nos demais solos estudados (TABELA 4).

Na última avaliação (127 DAE), houve efeito da interação saturação por bases e doses de $\mathrm{K}$ no solo (TABELA 5). Dentro de uma mesma $\mathrm{V} \%$, não houve diferença significativa. Porém, na saturação por bases de $70 \%$, associada a dose de $120 \mathrm{mg} \mathrm{kg}^{-1}$ de $\mathrm{K}\left(\mathrm{K}_{3}\right)$ e na saturação de $40 \%$, associada a dose $\mathrm{K}_{2}$, o número médio de entrenós por planta diminuiu.

Parece ter ocorrido, nesta dose $\left(\mathrm{K}_{3}\right)$, na maior saturação por bases $(70 \%)$, efeito de maior competição entre $\mathrm{Ca}, \mathrm{Mg}$ com o $\mathrm{K}$ (TABELA 1). A maioria dos trabalhos consultados evidencia que quando se altera a participação dos íons na CTC, há efeito direto na absorção catiônica pela planta e, portanto, reflexos no crescimento (Liebhardt, 1981). Além do mais, dependendo da dose de $\mathrm{K}$ aplicado ao solo, pode haver $\mathrm{O}$ chamado "consumo de luxo" de K pela planta, ocorrendo assim maior competição entre os três íons $(\mathrm{Ca}, \mathrm{Mg}$ e K) pelos sítios de troca, o qual interfere no crescimento e desenvolvimento da planta (Alves et al., 1988).

Rengel (1992) concluiu que existe o efeito do íoncomplementar entre o $\mathrm{Ca}$ e o $\mathrm{Mg}$ na interface solo/raiz, dependendo do cultivar utilizado, favorecendo assim a absorção de ambos em relação ao K. Já Grant \& Racz (1987) atribuíram a redução do crescimento da planta ao excesso de $\mathrm{Ca}$ e $\mathrm{Mg}$ na solução e não à deficiência induzida por ambos sobre o K, dado esse concordante com o de Mortvedt \& Khasawneh (1986), que descreveram haver um balanço de nutrientes no solo, responsável não só a limitações da produção, mas também sobre o crescimento da planta.

Para comprimento médio de entrenós (TABELA 
4), o comportamento foi semelhante ao ocorrido com a altura de plantas (TABELA 2), no que se refere ao efeito do $\mathrm{K}$ no solo. Assim, até a dose de $60 \mathrm{mg} \mathrm{kg}^{-1}$, houve resposta significativa em relação ao original do solo $(0,5$ $\mathrm{mmol}_{\mathrm{c}} \mathrm{dm}^{-3}$ ), isso independentemente da época de amostragem. Para tanto, Stromberger et al. (1994) atribuíram ao fato do $\mathrm{K}$ influenciar diretamente 0 crescimento celular pela ativação enzimática no transporte de $\mathrm{N}$ e, portanto, ser de fundamental importância na formação de tecidos vegetais.

O efeito do tipo de solo sobre o comprimento médio de entrenós foi inversamente relacionado ao número médio de entrenós por planta, ou seja, quanto maior o número menor o comprimento (TABELA 4). Nos solos mais argilosos que possuem maior CTC, maior será a quantidade de $\mathrm{Ca}$, $\mathrm{Mg}$ e $\mathrm{K}$ disponíveis para absorção pela planta, atribuindo-se ao $\mathrm{Ca}$ e $\mathrm{K}$ papel importante no alongamento celular e conseqüente crescimento da planta (Vasilas et al., 1988; Murtadha et al., 1989; Taiz \& Zeiger, 1991).

O efeito da saturação por bases no comprimento médio de entrenós foi significativo até a maturação (TABELA 4). Os valores foram mais elevados na saturação por bases de $70 \%$, visto que nesses valores, novamente, a quantidade de bases $(\mathrm{Ca}, \mathrm{Mg}$ e $\mathrm{K}$ ) trocáveis foi maior, independentemente do tipo de solo.

O comprimento de entrenós está diretamente relacionado com a altura da planta que, por sua vez, é decorrente do crescimento dos tecidos, altamente influenciado pela adição de K (TABELAS 2 e 4). Entretanto, houve relação inversa entre o número e 0 comprimento de entrenós nos diferentes solos estudados (TABELA 4). Tal comportamento, permitiu constatar que em solos de maior CTC e portanto maior reservatório de nutrientes, a planta compensou o menor número de nós com um maior comprimento de entrenós ao final do ciclo.

A produção de grãos por planta foi afetada pelo tipo de solo, onde verifica-se que não houve uma tendência lógica para o resultado obtido (TABELA 4). Como a maior produção foi obtida no Neossolo Quartzarênico, a explicação poderia ser atribuída à maior disponibilidade de nutrientes em solução no solo arenoso. Porém, constatase que não houve diferença entre este solo e o Latossolo Bruno, que pela sua CTC, apresenta maior quantidade total de nutrientes.

O efeito do $\mathrm{K}$ na produção de grãos foi o mesmo dos parâmetros de crescimento avaliados, ou seja, a partir da dose de $60 \mathrm{mg} \mathrm{kg}^{-1}$ de $\mathrm{K}$, não houve efeito significativo. Em teores menores de $\mathrm{Ca}$ e $\mathrm{Mg}$ no solo, a absorção o $\mathrm{K}$ pode ter sido incrementada, pois esse em maior disponibilidade ganha na competição pelos sítios de absorção, processo esse denominado por inibição competitiva. Dessa forma, a maior absorção de $\mathrm{K}$ em função da elevação do teor desse elemento no solo (TABELA 1), incrementa a translocação de fotossintatos para a espiga e conseqüentemente, para os seus grãos. Sobre tal comportamento, Mortvedt \& Khasawneh (1986) descreveram que o balanço de nutrientes no solo foi responsável por outras limitações no crescimento e não só na produção final de grãos.

TABELA 4 - Número e comprimento de entrenós por planta de milho em diferentes dias após a emergência (DAE), e produção de grãos por planta afetadas pela saturação por bases e teores de potássio em diferentes solos.

\begin{tabular}{|c|c|c|c|c|c|c|c|}
\hline \multirow{2}{*}{ Tratamento $^{1}$} & \multicolumn{3}{|c|}{ Número de entrenós } & \multicolumn{3}{|c|}{ Comprimento de entrenós } & \multirow{2}{*}{ Produção de grãos } \\
\hline & $29 \mathrm{DAE}$ & $57 \mathrm{DAE}$ & $127 \mathrm{DAE}$ & 29 DAE & $57 \mathrm{DAE}$ & $127 \mathrm{DAE}$ & \\
\hline & & & & ------------ & cm ---. & - & ------- g ------- \\
\hline NQ & $6,78 \mathrm{a}$ & $12,31 \mathrm{a}$ & $14,41 \mathrm{a}$ & 5,10 a & $11,57 \mathrm{~b}$ & $14,75 b$ & 94,48 a \\
\hline LV & $6,19 \mathrm{~b}$ & $11,22 \mathrm{~b}$ & $13,31 \mathrm{~b}$ & $4,88 \mathrm{~b}$ & $12,59 \mathrm{a}$ & $16,38 \mathrm{a}$ & $78,17 \mathrm{~b}$ \\
\hline LB & $6,37 \mathrm{~b}$ & $11,75 a b$ & $13,44 \mathrm{~b}$ & $4,75 \mathrm{~b}$ & $12,42 a b$ & $16,81 \mathrm{a}$ & $91,02 a b$ \\
\hline $\mathrm{V}_{40}$ & 6,42 & 11,62 & 13,77 & $4,75 \mathrm{~b}$ & $11,74 \mathrm{~b}$ & $15,77 \mathrm{~b}$ & 85,24 \\
\hline$V_{70}$ & 6,48 & 11,90 & 13,67 & 5,07 a & $12,65 \mathrm{a}$ & 16,19 a & 90,54 \\
\hline $\mathrm{K}_{1}$ & 6,37 & 11,25 & 13,83 & $4,55 \mathrm{~b}$ & $10,87 b$ & $15,06 \mathrm{~b}$ & $74,58 \mathrm{~b}$ \\
\hline $\mathrm{K}_{2}$ & 6,48 & 12,00 & 13,67 & $5,00 \mathrm{a}$ & $12,50 \mathrm{a}$ & 16,18 a & $91,07 a b$ \\
\hline $\mathrm{K}_{3}$ & 6,46 & 11,75 & 13,71 & $5,01 \mathrm{a}$ & $12,74 \mathrm{a}$ & $16,33 \mathrm{a}$ & $96,97 \mathrm{a}$ \\
\hline $\mathrm{K}_{4}$ & 6,48 & 12,04 & 13,67 & 5,07 a & $12,67 \mathrm{a}$ & $16,35 \mathrm{a}$ & $88,93 \mathrm{ab}$ \\
\hline CV (\%) & 6,26 & 11,00 & 3,65 & 9,26 & 13,46 & 11,29 & 29,21 \\
\hline $\mathrm{S}$ & * & * & * & * & * & * & * \\
\hline V\% & & & & * & * & & \\
\hline $\mathrm{K}$ & & & & * & * & * & * \\
\hline
\end{tabular}


TABELA 5 - Número de entrenós por planta de milho aos 127 (DAE) em função das doses de potássio e da saturação por bases (Desdobramento das interações significativas da análise de variância).

\begin{tabular}{ccc}
\hline Dose de $\mathrm{K}$ & \multicolumn{2}{c}{ Saturações por bases } \\
\hline $\mathrm{Mg} \mathrm{kg}^{-1}$ & $\mathrm{~V}_{70}$ \\
0 & $13,92 \mathrm{aA}$ & $13,75 \mathrm{aA}$ \\
60 & $13,42 \mathrm{aB}$ & $13,92 \mathrm{aA}$ \\
120 & $13,92 \mathrm{aA}$ & $13,50 \mathrm{aB}$ \\
240 & $13,83 \mathrm{aA}$ & $13,50 \mathrm{aA}$ \\
\hline
\end{tabular}

Médias seguidas da mesma letra, minúscula na vertical e maiúscula na horizontal, não diferem estatisticamente pelo teste de Tukey a $5 \%$.

\section{CONCLUSÕES}

- O desenvolvimento e a produção de grãos do milho aumentou até a adição de $60 \mathrm{mg} \mathrm{kg}^{-1}$ de $\mathrm{K}$ ao solo.

- O crescimento do milho foi mais rápido no solo mais arenoso, até o florescimento masculino.

- Solos com maior capacidade de troca catiônica proporcionaram maior comprimento de entrenós.

- O comprimento médio de entrenós foi inversamente relacionado ao número médio de entrenós por planta, em função do tipo de solo.

\section{REFERÊNCIAS BIBLIOGRÁFICAS}

ALVES, A.C.; BRAUNER, J.L.; CORDEIRO, D.S.; ZONTA, E.P.; CORREA, L.A.V. Exigências nutricionais em potássio, cálcio e magnésio do sorgo sacarino. Pesquisa Agropecuária Brasileira, v.23, p.529-536, 1988.

ANDREOTTI, M. Estudo da interação calcário e zinco em milho. Botucatu, 1995. 66p. Dissertação (Mestrado)Faculdade de Ciências Agronômicas, Universidade Estadual Paulista.

CARVALHO, W.A.; SPINDOLA, C.R.; PACOLLA, A.A. Levantamento de solos da Fazenda Lageado- Estação Experimental 'Presidente Médici'. Botucatu: UNESP/FCA, 1983. 95p.

FERREIRA, M.E.; CRUZ, M.C.P.; FERREIRA JR.; M.E. Avaliação da fertilidade empregando o sistema IAC de análise de solo. Jaboticabal: UNESP/FCAV, 1990. 94p.

FURLANI, A.M.C.; BATAGLIA, O.C.; LIMA, M. Crescimento diferencial de linhagens de milho em solução nutritiva com baixo nível de potássio. Bragantia, v.45, p.303-316, 1986.

GRANT, C.A.; RACZ, G.J. The effect of $\mathrm{Ca}$ and $\mathrm{Mg}$ concentrations in nutrient solution on the dry matter yield and $\mathrm{Ca}, \mathrm{Mg}$ and $\mathrm{K}$ content of barley (Hordeum vulgare L.). Canadian Journal of Soil Science, v.67, p.857-865, 1987.
KARLEN, D.L.; FLANNERY, R.L.; SADLER, E.J. Nutrient and dry matter accumulation rates for high yielding maize. Journal of Plant Nutrition, v.10, p.1409-1417, 1987.

LIEBHARDT, W.C. The basic cation saturation ratio concept and lime and potassium recommendations an Delaware's Coastal plain soils. Soil Science Society of America Journal, v.45, p.544-549, 1981.

LIEROP, W. van; MARTEL, Y.A.; CESCAS, M.P. Onion response to lime on acid histosols as affected by $\mathrm{Ca} / \mathrm{Mg}$ ratios. Soil Science Society of America Journal, v.43, p.1172-1177, 1979.

MALAVOLTA, E. Elementos de nutrição mineral de plantas. São Paulo: Agronômica Ceres, 1980. p.219-251: A avaliação do estado nutricional.

MEURER, E.J.; ANGHINONI, I. Disponibilidade de potássio e sua relação com parâmetros de solo. Revista Brasileira de Ciência do Solo, v.17, p.377-382, 1993.

MODEL, N.S.; ANGHINONI, I. Resposta do milho a modos de aplicação de adubos e técnicas de preparo do solo. Revista Brasileira de Ciência do Solo, v.16, p.55-59, 1992.

MORTVEDT, J.J.; KHASAWNEH, F.E. Effects of growth responses on cationic relationships in plants. Soil Science, v.141, p.200-207, 1986

MURTADHA, H.M.; MARANVILLE, J.W.; CLARK, R.B.; CLEGG, M.D. Effects of temperature and relative humidity on growth and calcium uptake, translocation, and accumulation in sorghum. Journal of Plant Nutrition, v.12, p.535-543, 1989.

OLIVEIRA, E.L. Rendimento de matéria seca e absorção de cálcio e magnésio pelo milho em função da relação $\mathrm{Ca} / \mathrm{Mg}$ do solo. Revista Brasileira de Ciência do Solo, v.17, p.383-388, 1993.

RAIJ, B.van.; CANTARELLA, H.; QUAGGIO, J.A.; FURLANI, A.M.C. Recomendações de adubação e calagem para o Estado de São Paulo. 2. ed. Campinas: Instituto Agronômico/ Fundação IAC, 1996. 285p.

RENGEL, Z. Modeling magnesium uptake from an acid soil: IV Depletion of magnesium, calcium, and potassium from soluble and exchangeable phase. Communications in Soil Science and Plant Analysis, v.23, p.165-174, 1992.

SILVA, J.E. Balanço de cálcio e magnésio e desenvolvimento do milho em solos sob cerrado. Pesquisa Agropecuária Brasileira, v.15, p.329-33, 1980.

STROMBERGER, J.A.; TSAI, C.Y.; HUBER, D.M. Interactions of potassium with nitrogen and their influence on growth and yield potential in maize. Journal of Plant Nutrition, v.17, p.19-37, 1994.

TAIZ, L.; ZEIGER, E. Plant physiology. Belmont: The Benjamin Cummings, 1991. p.426-449.

VASILAS, B.L.; ESGAR, R.J.; WALKER, W.M.; MAINZ, M.J. Effect of tillage on corn response to potassium fertility. Communications in Soil Science and Plant Analysis, v.19, p.141-151, 1988.

WILKINSON, R.E.; DUNCAN, R.R. Magnesium influence on calcium $\left({ }^{45} \mathrm{Ca}^{+2}\right)$ absorption by sorghum root tips. Journal of Plant Nutrition, v.16, p.1917-1920, 1993

Recebido em 25.05.99 